POLICY FORMULATION STUDY OF BANYUMAS HEALTH CARD IN BANYUMAS REGENCY

\title{
STUDI FORMULASI KEBIJAKAN KARTU BANYUMAS SEHAT DI KABUPATEN BANYUMAS
}

\author{
Program Studi Ilmu Administrasi \\ Universitas Jenderal Soedirman \\ wetjung@yahoo.co.id
}

Etjung Widhiarto, Slamet Rosyadi, dan Denok Kurniasih

\begin{abstract}
In decentralization era, the health problem widely used to campaign as populist program in local election. Consequently, some public policies are easily formulate after it, especially Banyumas Health Card Policy. Therefore, the researcher aim to analyze the formulation process of Banyumas Health Card Policy. A multiple streams theory of John W. Kingdon which consist of problem, policy, and political streams is used by researcher. Then, all streams are coupling by policy entepreneur (PE) to open policy window. Based on the result, it can be found that all streams are not running simultaneously. But, the political stream is a dominant streams which push other streams are faster. So, PE use it to open policy window.
\end{abstract}

\section{Keywords : Multiple Streams, Policy Entrepreneur, Policy Formulation and Policy Window}

\begin{abstract}
ABSTRAK
Pada era desentralisasi, permasalahan kesehatan banyak digunakan sebagai program populis dalam pemilihan kepala daerah. Sehingga beberapa kebijakan publik sangat mudah terbentuk setelah melalui proses pemilihan kepala daerah, khususnya Kebijakan Kartu Banyumas Sehat. Oleh karena itu, peneliti bermaksud menganalisis proses formulasi Kebijakan Kartu Banyumas Sehat. Peneliti menggunakan teori multi arus John W. Kingdon (1995) yang terdiri dari arus masalah, kebijakan, dan politik. Adapun ketiga arus tersebut kemudian digabungkan oleh Policy Entrepreneur (PE) untuk membuka Policy Window. Berdasarkan hasil penelitian, dapat ditemukan bahwa faktanya ketiga arus tidak berjalan simultan, karena arus politik memiliki kekuatan dominan yang dapat mendorong arus lain. Konsekuensinya, PE menggunakan arus politik secara dominan untuk membuka Policy Window.
\end{abstract}

Kata kunci : Formulasi Kebijakan, Multiple Streams, Policy Entrepreneur, dan Policy Window. 


\section{A. PENDAHULUAN}

Dewasa ini kesehatan merupakan bagian dari ukuran dasar kesejahteraan manusia. Secara konstitusional dalam pasal $28 \mathrm{H}$ dan 34 ayat 2 negara dengan tegas memberikan jaminan bahwa rakyat berhak mendapatkan pelayanan kesehatan yang adil dan bermartabat. Namun, karena tingginya angka kemiskinan dan biaya pelayanan kesehatan, banyak masyarakat miskin yang tidak dapat menjangkau pelayanan kesehatan tersebut. Disisi lain, pemerintah pusat juga memiliki keterbatasan memberikan pelayanan kesehatan yang adil kepada masyarakat. Konsekuensinya, beberapa pemerintah daerah menyikapinya dengan membuat kebijakan kesehatan lokal.
Pada tingkatan lokal, keterbatasan dapat dilihat pada pelayanan kesehatan di Kabupaten Banyumas, Jawa Tengah. Berdasarkan data Program Perlindungan Sosial (PPLS) 2011 Tim Nasi.onal Percepatan Penanggulangan Kemiskinan (TNP2K) penduduk miskin di Banyumas berjumlah 889.264 jiwa. Namun, pada tahun 2013 jumlah penduduk yang terdaftar sebagai peserta Jamkesmas hanya 590.807 jiwa, artinya terdapat 298.457 jiwa yang tidak terjamin kebutuhan kesehatannya. Sementara itu, ketersedian anggaran juga masih bermasalah. Berikut adalah besaran anggaran pelayanan kesehatan di Kabupaten Banyumas:

Tabel 1.1

Anggaran Jaminan Kesehatan Masyarakat dan Daerah Kabupaten Banyumas

\begin{tabular}{ccrr}
\hline Tahun & Jamkesmas & Jamkesda & \multicolumn{1}{c}{ Total } \\
\hline $\mathbf{2 0 0 8}$ & 7.021 .685 .848 & 820.000 .000 & 7.841 .685 .848 \\
$\mathbf{2 0 0 9}$ & 13.221 .065 .646 & 3.100 .000 .000 & 16.321 .065 .646 \\
$\mathbf{2 0 1 0}$ & 10.362 .955 .356 & 3.000 .000 .000 & 13.362 .955 .356 \\
$\mathbf{2 0 1 1}$ & 10.139 .972 .000 & 4.025 .000 .000 & 14.164 .972 .000 \\
$\mathbf{2 0 1 2}$ & 5.501 .201 .000 & 9.000 .000 .000 & 14.501 .201 .000 \\
\hline
\end{tabular}

Sumber : Dinas Kesehatan Kabupaten Banyumas 2013

Berdasarkan data pada tabel tersebut dapat diambil beberapa informasi bahwa anggaran Jamkesmas terbesar terjadi pada tahun 2009 sebesar Rp 13.221.065.646, sedangkan setelah tahun tersebut anggaran Jamkesmas selalu mengalami penurunan. Hal ini dikarenakan adanya pelimpahan kewenangan permasalahan kesehatan dari pemerintah pusat ke pemerintah daerah. Konsekuensinya anggaran Jamkesda yang bersumber dari APBD harus dinaikkan, dimana anggaran terbesar terjadi pada tahun 2012 sebesar Rp. 9.000.000.000. Jika dilihat secara agregrat pada tahun 2012 jumlah anggaran kesehatan di Kabupaten Banyumas sebesar Rp. 14.501.201.000. Namun, jika mengggunakan indeks maksimal pembiayaan Jamkesmas 
sebesar 3 juta, besaran anggaran kesehatan tersebut hanya mampu menjangkau 0,54 persen atau 4.833 jiwa dari total penduduk miskin di Kabupaten Banyumas.

Fakta lain menunjukkan bahwa masih banyak masyarakat miskin yang harus menanggung pembiayaan kesehatan secara mandiri. Terbatasnya biaya jaminan dan mahalnya biaya pengobatan merupakan faktor penyebabnya. Berdasarkan data tagihan Jamkesda Rumah Sakit Margono dilaporkan bahwa dari total tagihan Jamkesda sebesar Rp. 11.921.921.369, pemerintah Kabupaten Banyumas dan Provinsi Jawa Tengah menanggung pembiayaan masing-masing sebesar $\mathrm{Rp}$ 7.934.134.377 dan Rp 2.763.837.767. Sedangkan sisanya sebesar Rp. 1.223.949.225 harus ditanggung oleh pasien. Tingginya beban pasien ini lah yang menjadi keluhan warga miskin di Kabupaten Banyumas.

Dalam beberapa pemilihan kepala daerah, kasus rendahnya akses kesehatan bagi warga miskin banyak dimanfaatkan sebagai program kampanye. Bahkan aktor pengusung program dapat memenangkan proses pemilihan kepala daerah tersebut. Kesuksesan tim Jokowi Ahok dalam pemilihan gubernur DKI Jakarta merupakan contoh fenomena tersebut, dimana pasangan Jokowi-Ahok menggunakan program Kartu Jakarta Sehat sebagai program unggulan kampanye. Kesuksesan ini menginisiasi tim Husein-Budhi dalam Pilkada Kabupaten Banyumas tahun 2013, dimana tim tersebut menggunakan program replika Kartu Jakarta Sehat yaitu Kartu Banyumas Sehat (KBS) sebagai program unggulan kampanye. Bahkan dalam konteks kekinian, kesuksesan yang sama juga terdjadi pada Pilkada Kabupaten Cilacap dan Pilpres 2014. Berdasarkan fenomena tersebut, artinya beberapa kebijakan publik "dilahirkan" dari sebuah proses politik yang sangat massif (baca:pemilihan umum).

Dalam menguraikan proses formulasi kebijakan, peneliti menggunakan panduan teori multi arus (multiple stream theory) dari John W. Kingdon. Teori ini dikembangkan dari garbage can theory yang dikemukakan oleh Cohen, March, dan Olsen pada tahun 1972, dimana mereka berupaya menjelaskan perilaku pengambilan keputusan dalam organisasi anarkhi (banyaknya partisipan yang keluar masuk, bertujuan ambigu, tidak memahami tingkatan pengambilan keputusan, dan gamang mengambil peran). Oleh karena itu, Cohen dkk. Memperkenalkan pendekatan empat arus dalam pengambilan keputusan yaitu problem, solution, participant, dan choice opportunities (Cohen et.al, 1972; Hill, 2005; dan Kingdon, 1995). Berdasarkan teori ini, kemudian Kingdon merekonstruksi bahwasanya terdapat tiga arus utama dalam formulasi kebijakan publik yaitu problem, policy, dan political streams. Pertama, arus masalah (problem stream) merupakan tahapan agenda setting dalam formulasi kebijakan, mengapa kondisi sosial tertentu dipermasalahkan dan dijadikan sebagai agenda kebijakan?. Terdapat tiga hal yang mempengaruhi arus masalah yaitu 
indikator (ukuran-ukuran yang dikeluarkan oleh lembaga kredibel seperti tingkat kemiskinan, pengangguran, pertumbuhan ekonomi), peristiwa besar (peristiwa yang menyita perhatian publik seperti bencana dan pemilu), dan umpan balik publik (Beland, 2005; Lewish dan Stephen, 2008; dan Teodorovic, 2008).

Kedua, arus kebijakan (policy stream) yaitu gagasan-gagasan yang muncul sebagai solusi atas problem kebijakan. Kingdon menganalogikan proses mencari solusi ini layaknya memasak sebuah sup, sehingga kemudian disebut dengan policy primeval soup. Proses diawali dengan munculnya banyak gagasan yang kemudian dikombinasikan, diujikan dan dibuatkan alternatif terbaiknya. Ketiga, arus politik yaitu situasi politik yang ikut mendorong perhatian publik, khususnya policy maker. Elemen dari arus politik ini adalah national mood, tekanan organisasi politik, dan perubahan pandangan administrator (Carrillo, 2007; Larkin, 2010; Travis dan Nikolas, 2002; dan Zahariadis, 2006).

Ketiga arus tersebut akan dipertemukan oleh Policy Entrepreneur (PE) untuk membuka jendela kebijakan (policy window). Artinya kebijakan publik akan terbentuk jika PE mendorong dan mempertemukan ketiga arus tersebut. Adapun PE adalah aktor baik dari dalam ataupun luar pemerintahan yang dengan rela menginvestasikan waktu, energi, reputasi, uang, dan pegawai untuk mencapai tujuan dan nilai yang diinginkan (Jean, 2012; Jenkind dan Les
Alm, 2003). Oleh karena itu berdasarkan uraian empiris dan teoritis, penelitian ini bertujuan untuk menganalisis proses formulasi pada kebijakan Kartu Banyumas Sehat.

\section{B. METODE PENELITIAN}

Formulasi kebijakan publik yang notabene kompleks dan seringkali terdapat motif atau agenda yang bersifat hidden, maka peneliti menggunakan metode penelitian kualitatif. Hal ini karena metode kualitatif merupakan metode yang digunakan untuk mengamati perilaku, persepsi, motivasi, atau tindakan dengan menempatkan informan sebagai subjek penelitian, sehingga mampu didapatkan esensi tentang apa, bagaimana, kapan, dan dimana suatu hal terjadi (Berg, 2001; Branen, 1995; Moleong, 2005; dan Sugiyono, 2007). Adapun peneliti menggunakan teknik purposive sampling untuk memilih informan penelitian, karena peneliti telah memiliki pengetahuan dan pertimbangan dalam memilih subjek penelitian.

Penelitian ini dilakukan di Kabupaten Banyumas dan dimulai dari bulan Maret-Juni 2014. Sedangkan sasaran penelitiannya adalah bupati dan wakil bupati periode 2013-2018, anggota DPRD periode 2009-2014, Dinas Kesehatan, DPPKAD, Bappeda, perguruan tinggi, ormas, dan media. Adapun untuk mengukur validitas penelitian, peneliti menggunakan triangulasi sumber dengan membandingkan data hasil pengamatan dan wawancara, keadaan dengan perspektif orang, dan hasil wawancara 
dengan isi dokumen (Moleong, 2005: 330).

\section{HASIL DAN PEMBAHASAN}

Fenomena pada era desentralisasi, beberapa kebijakan publik mulai dibentuk sejak proses pemilihan umum. Dimana kebijakan tersebut merupakan program populis yang ditujukan untuk memenangkan pemilihan umum. Kebijakan Jaminan Kesehatan Daerah Kabupaten Banyumas atau yang disebut dengan Kartu Banyumas Sehat (KBS) merupakan potret dari fenomena tersebut. KBS digunakan oleh tim Husein-Budhi untuk memenangkan pemilihan kepala daerah Kabupaten Banyumas. Sejak saat itulah, permasalahan kesehatan mulai massif dibicarakan hingga menjadi kebijakan publik ditingkat lokal Banyumas. Oleh karena itu dengan menggunakan guideline theory Kingdon, peneliti melakukan analisis proses formulasi kebijakan Kartu Banyumas Sehat. Berikut adalah deskripsi proses formulasi Kartu Banyumas Sehat:

1. Arus Masalah (Problem Stream)

Dalam RPJMD Kabupaten

Banyumas, kesehatan merupakan salah satu bagian dari isu strategis. Jika ditelusuri permasalahan kesehatan di Kabupaten Banyumas memang sangat kompleks, seperti tingginya HIV/AIDS, angka kematian ibu, rendahnya status gizi masyarakat dan akses kesehatan. Namun, policy maker kemudian memandang bahwa akses kesehatan adalah permasalahan yang lebih substansial dan perlu diselesaikan.

Ada beberapa faktor yang mendorong permasalahan akses kesehatan menjadi perhatian policy maker. Pertama, adanya laporan dinas kesehatan dan kajian tim Labsos FISIP Unsoed yang menyebutkan bahwa masih banyak warga Banyumas yang tidak dapat mengakses layanan kesehatan. Pada tahun 2008 berdasarkan data dalam kajian tim Labsos FISIP Unsoed jumlah masyarakat yang tidak memiliki jaminan kesehatan sebanyak 94.290 jiwa, sedangkan lima tahun kemudian berdasarkan data Dinas Kesehatan Banyumas pada tahun 2013 jumlahnya meningkat menjadi sebesar 298.457 jiwa. Kedua, adanya pemilihan kepala daerah Kabupaten Banyumas 2013, dimana pasangan HuseinBudhi mengangkat program akses kesehatan yang dinamakan Kartu Banyumas Sehat. Sehingga perhatian publik mengarah pada program tersebut, apalagi pasangan Husein-Budhi adalah kandidat yang diperhitungkan memiliki peluang untuk memenangkan pilkada Kabupaten Banyumas. Ketiga, adanya preferensi dan kepedulian yang kuat terhadap permaslahan akses kesehatan. Preferensi ini tentunya dilatarbelakangi oleh nilai atau motif yang dibawa oleh masingmasing aktor. Namun sebelum mengetahui preferensi aktor, peneliti telah memetakan aktor 
yang terlibat dalam formulasi KBS yaitu :

Tabel 1.2. Roadmap Aktor dalam Formulasi KBS 2013

\begin{tabular}{ll}
\hline \multicolumn{1}{c}{ Kategori Stakeholder } & \multicolumn{1}{c}{ Aktor } \\
\hline Stakeholder Kunci & Eksekutif dan Legislatif Kabupaten Banyumas \\
\hline Stakeholder Primer & Tim sukses Bupati dan Wakil Bupati terpilih \\
\hline Stakeholder Sekunder & Akademisi Unsoed, Ormas (SRMI), Media
\end{tabular}

Sumber: data primer

Berdasarkan tabel tersebut dapat diterangkan bahwa stakeholder kunci merupakan aktor yang memiliki kewenangan legal membuat kebijakan. Sedangkan stakeholder primer yaitu kelompok yang memiliki kaitan langung dengan kebijakan yang sedang dibahas. Adapun stakeholder sekunder merupakan aktor yang tidak memiliki kepentingan langung, namun memiliki kepedulian terhadap pokok permasalahan kebijakan. Setiap aktor dalam kebijakan membawa kepentinganya masingmasing.

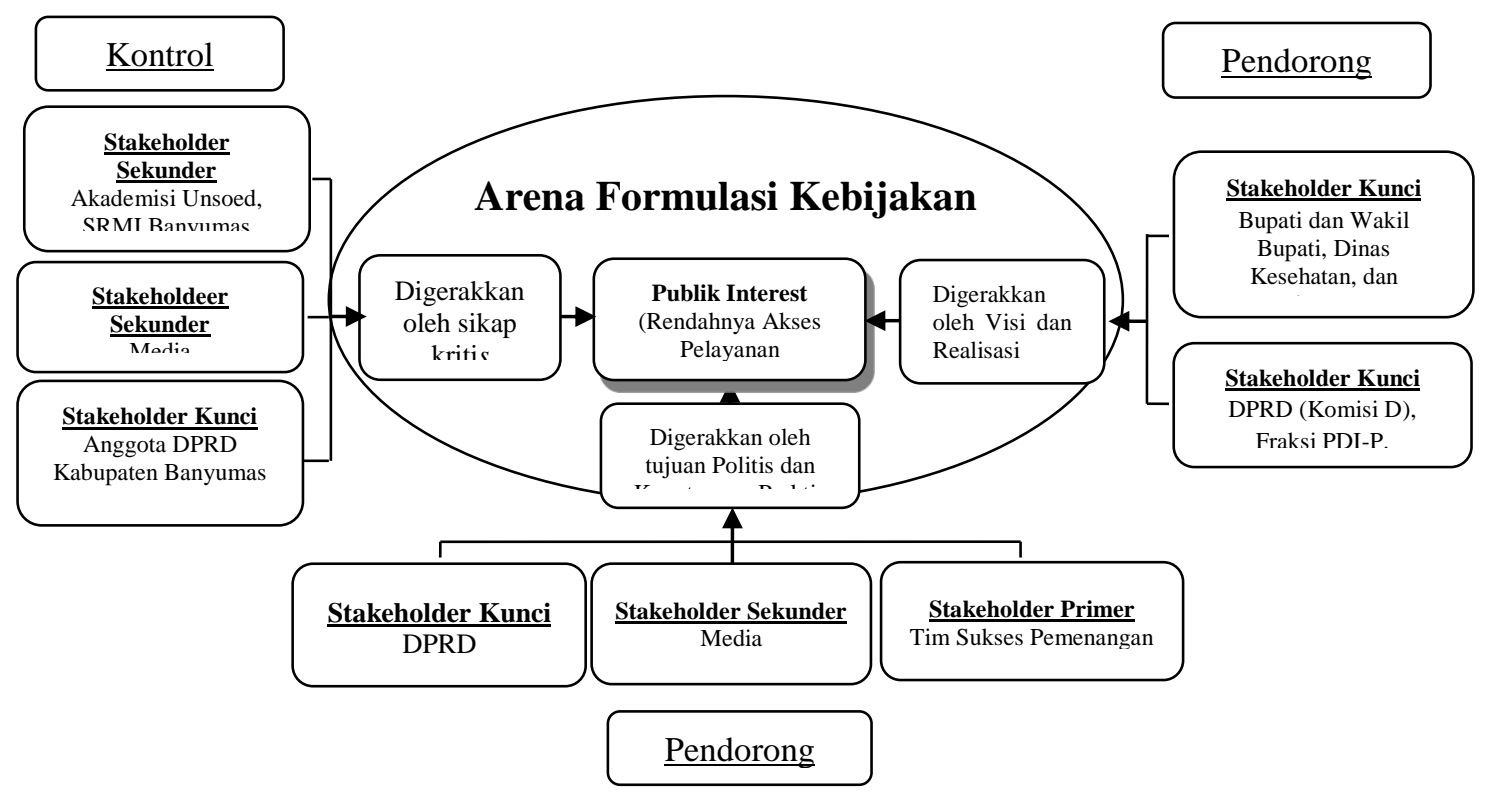

Gambar 1. Roadmap Nilai Kebijakan Para Aktor dalam Formulasi Kebijakan Kartu Banyumas Sehat

a. Aktor yang digerakkan oleh visi dan realisasi janji

Aktor ini bergerak karena didorong oleh keinginan untuk membangun dan mewujudkan janji-janji yang pernah disampaiakan kepada publik. Adapun aktor yang 
merepresentasikan motif ini adalah bupati dan wakil bupati terpilih, anggota DPRD khususnya komisi D dan FPDIP. Aktor dengan motif ini cenderung menjadi kekuatan pendorong masalah KBS menjadi kebijakan publik.

b. Aktor yang digerakkan oleh tujuan politis dan keuntungan praktis

Aktor ini sangat antusias dalam formulasi KBS karena didorong oleh motif politik dan keuntungan ekonomis. Aktor yang berperan dengan motif ini yaitu beberapa anggota DPRD yang akan mencalonkan kembali dalam pileg 2014, tim sukses pemenangan bupati, dan media. Motif ini cenderung mendorong KBS menjadi kebijakan publik. Berikut adalah struktur motif aktor dalam formulasi KBS.

c. Aktor yang digerakkan oleh sikap kritis

Aktor ini terlibat dalam proses formulasi KBS karena dimotivasi oleh kepedulian mereka terhadap permasalahan yang sedang dikaji. Media, Akademisi Unsoed, dan beberapa anggota DPRD Kabupaten Banyumas adalah representasi dari motif ini. Sedangkan motif ini cenderung menjadi aktor pengontrol dan pada formulasi KBS memberikan kekuatan pendukung, dimana dinyatakan secara tegas bahwa akses kesehatan adalah permasalahan publik yang perlu diselesaikan di Kabupaten Banyumas.

Berdasarkan uraian fakta tersebut secara konseptual dalil teoritik problem stream yang dibangun oleh Kingdon memang didukung oleh fakta empiris. Kingdon mengatakan bahwa sebuah permasalahan tertentu akan dianggap penting sebagai masalah publik dan perlu diselesaikan jika terdapat beberapa hal seperti indikator, focusing event, dan feedback (Carrillo, 2007 dan Travis, 2002). Secara empiris, indikator diwujudkan melalui laporan Dinas Kesehatan dan kajian tim Labsos FISIP Unsoed tentang rendahnya akses kesehatan. Adapun Pilkada Kabupaten Banyumas merupakan focusing event, dimana peristiwa ini mampu mengarahkan perhatian publik dan publik menganggap bahwa akses kesehatan merupakan kebutuhan mendesak (feedback). Menurut Kingdon (2001) dan Alan (2008) peristiwa besar baik krisis, bencana alam, pesawat jatuh, atau apapun akan memberikan dorongan pada permasalahan publik tertentu menjadi agenda kebijakan. Birkman et.al (2008) memberikan fakta besar dimana bencana Tsunami menjadi faktor pendorong yang sangat massif terhadap agenda perdamaian RI dan GAM.

Disisi lain, menurut Dunn (dalam Wibawa dkk., 2003:190- 
198) permasalahan akses menjadi perhatian para policy maker disebabkan oleh nalar etika yang dibangun. Nalar artinya mampu diterima oleh rasio atau otak manusia, laporan yang berupa angka-angka merupakan asosiasi konsep nalar. Sedangkan etika berkaitan dengan apa yang dianggap baik dan buruk, dimana KBS seolah-olah diibaratkan dengan upaya baik untuk membantu kelompok yang tidak mampu. Sehingga dengan membantu kelompok yang tidak mampu akan mewujudkan keadilan. Hal ini lah yang kemudian memberikan kekuatan dan opini publik untuk mendorong permasalahan akses menjadi agenda kebijakan.

2. Arus Politik (Political Stream)

Arus ini terkait dengan situasi politik di Kabupaten Banyumas yang mempengaruhi perhatian publik untuk mendorong atau menghambat permasalahan akses kesehatan menjadi kebijakan publik. Kondisi politik lokal (local mood) pada saat itu banyak dipengaruhi oleh adannya Pilkada Kabupaten Banyumas, dimana pasangan Husein-Budhi mengangkat program akses kesehatan dalam bentuk KBS. Menurut Arifin (2001) setiap kosntelasi politik setiap aktor yang berkepentingan akan melakukan komunikasi politik dengan citra dan opini publik. Akhirnya, KBS adalah wujud dari citra dan opini publik.
Setelah pasangan Husein-Budhi terpilih menjadi Bupati dan Wakil Bupati, nuansa lokal saat itu semakin klimaks. Publik menuntut realisasi janji politik . Secara tidak langsung, permasalahan akses kesehatan menjadi isu yang strategis. Konsekuensinya, hal ini menimbulkan perubahan pandangan pemerintah, dimana pemerintahan baru lebih fokus pada permasalahan kesehatan karena merupakan realisasi janji politik. Hal ini berbeda dengan pemerintahan sebelumnya yang menekankan pada permasalahan investasi, dimana investasi juga merupakan salah satu upaya realisasi janji politik bupati sebelumnya. Selain itu, kondisi ini menimbulkan pro dan kontra publik. Namun media cenderung bersikap pro, artinya ikut menuntuk agar KBS segera di realisasikan. Sehingga kondisi ini semaki mendorong permasalahan akses kesehatan menjadi isu yang sangat strategis.

Jika mengacu pada uraian tersebut, elemen pembentuk political stream Kingdon dapat menjelaskan fakta empiris aspek politik dalam formulasi KBS. Carrillo (2007) mengatakan national atau lokal mood, perubahan pandangan pemerintah, dan tekanan organisasi politik merupakan aspek politis yang menjadi pendorong massif dalam formulasi kebijakan publik. Apalagi peran media yang juga 
ikut memberikan dorongan membentuk opini publik dan situasi kebatinan lokal. Ndlovu (2006) dan Kingdon (1995) bahkan mengatakan media terkadang sangat tendensius mengcover permaslahan empiris dengan cara dramatis, sehingga membuat media menjadi kelompok yang mampu mempengaruhi kebijakan publik.

3. Arus Kebijakan (Policy Stream)

Dalam konsep teoritik Kingdon arus kebijakan adalah proses bertarungnya ide atau gagasan sebagai proposal kebijakan yang diibaratkan dengan memasak sup (policy primeval soup). Nuansa Kebijakan Kartu Banyumas Sehat yang dituangkan dalam Perda Kabupaten Banyumas No. 14 tahun 2013 memang bermula dari Raperda Komisi D DPRD Kabupaten Banyumas yang disusun oleh Tim Labsos FISIP Unsoed sebagai policy Communitiesnya. Ditengah proses pembuatan raperda tersebut banyak ide-ide yang muncul, ada yang beranggapan bahwa seharusnya bukan pelayanan gratis, namun pelayanan yang adil. Selain itu, studi banding ke Jembrana dan Surakarta dihasilkan dua gagsan yaitu tentang stratifikasi pelayanan kesehatan dan model kelembagaan penyelenggara layanan. Dalam konsep Kingdon, proses munculnya ide dinamakan dengan ideas floating. Kemudian ide tersebut dirangkum menjadi raperda (combination of ideas).

$\begin{array}{lrr}\text { Ketika } & \text { raperda } & \text { telah } \\ \text { disusun, kemudian } & \text { policy } \\ \text { entrepreneur menggunakannya } & \text { mebuah } \\ \text { untuk menyusun } & \text { sebijakan } \\ \text { rancangan proposal } & \text { kebian, } \\ \text { baru (baca: KBS). } & \text { Namun, } \\ \text { rancangan ini } & \text { kemudian } \\ \text { diimplementasikan } & \text { terlebih } \\ \text { dahulu dengan } & \text { mekanisme }\end{array}$
peraturan bupati, karena bupati dan wakil bupati terpilih dituntut untuk merealisasikan janjinya. Sehingga proses mencari alternatif terbaik pada pembuatan Perda No. 14 tahun 2013, akhirnya banyak diwarnai adanya pemakluman bersama. Argumen yang muncul yaitu beberapa aktor tidak mempermasalahkan nama yang penting esensinya, beberapa aktor memaklumi karena visi dan misi pemimpin memang harus didukung, dan beberapa aktor memaklumi karena tidak ingin menabrak kekuatan yang lebih besar yang berimbas pada karier politik mereka.

4. Policy Window

Policy Window adalah kondisi yang memungkinkan bersatunya tiga arus menjadi sebuah kebijakan publik, dimana untuk mencapai kondisi ini diperlukan aktor yang dinamakan policy entrepreneur (Chretien, 2002). Adapun policy entrepreneur adalah individu atau organisai baik dari dalam atau luar pemerintahan (bukan akademisi) 
yang mengidentifikasi, membenntuk, dan mendorong perhatian aktor kebijakan lain terhadap masalah dan atau solusi yang sedang dikaji untuk mendapatkan keuntungan. Sehingga untuk mencapai tujuan tersebut PE akan menginvestasikan uang, waktu, dan sumber dayanya (Carrillo, 2007; Chertien, 2002; dan Perkman, 2003).

Berdasarkan kategori policy entrepreneur dan pengamatan empiris, peneliti menyimpulkan bahwa aktor yang berperan sebagai PE dalam formulasi kebijakan Kartu Banyumas Sehat adalah Bupati dan Wakil Bupati terpilih dan media. Bupati dan wakil bupati terpilih merupakan aktor intern pemerintah, sedangkan media merupakan aktor ekstern pemerintah. Keduanya mengidentifikasi, membentuk, dan mendorong perhatian publik untuk memperhatikan permasalahan akses kesehatan dengan menginvestasikan uang, tenaga, dan waktunya. Faktanya bupati dan wakil bupati terpilih melakukan kampanye, diskusi, dan menerbitkan replika KBS demi tujuan memenangkan pilkada tercapai. , setelah terpilih Husein-Budhi kemudian mendorong pembangunan dan APBD pada bidang kesehatan. Berikut adalah tabel APBD Perubahan Kabupaten Banyumas tahun 2013:

Tabel 1.3.

Kenaikan Anggaran Belanja Pemerintah Kabupaten Banyumas Pada beberapa Bidang Urusan Wajib Pemerintah Daerah

\begin{tabular}{|c|c|c|c|}
\hline \multirow{2}{*}{$\begin{array}{c}\text { Urusan } \\
\text { Pemerintah } \\
\text { Daerah }\end{array}$} & \multicolumn{2}{|c|}{ Anggaran Belanja Daerah } & \multirow{2}{*}{$\begin{array}{l}\text { Kenaikan/ } \\
\text { Penurunan }\end{array}$} \\
\hline & $\begin{array}{c}\text { Sebelum } \\
\text { Perubahan }\end{array}$ & Sesudah Perubahan & \\
\hline Pendidikan & 1.045 .321 .379 .190 & 1.106 .753 .829 .171 & 61.432 .449 .981 \\
\hline Kesehatan & 258.178.487.495 & 317.329 .436 .140 & 59.150 .948 .645 \\
\hline $\begin{array}{l}\text { Pekerjaan } \\
\text { Umum }\end{array}$ & 237.522.128.613 & 268.097.050.089 & 30.574 .921 .476 \\
\hline
\end{tabular}

Sumber : DPPKAD Kabupaten Banyumas Tahun 2013

Berdasarkan tabel tersebut ketiga aspek pembangunan tersebut memang mengalami kenaikan, namun dapat diambil informasi bahwa pemerintahan era Bupati Achmad Husein dan Budi Setiawan ingin menekankan pada bidang kesehatan. Indikatornya anggaran kesehatan dinaikkan sebesar 22 persen dibandingkan dengan tahun lalu. Sedangkan pendidikan dan pekerjaan umum masing-masing naik 5 persen dan 12 persen dibandingkan dengan 
anggaran sebelum perubahan. Fakta ini tentunya menunjukkan adanya upaya mendorong anggaran publik pada bidang kesehatan.

Selain itu, media juga dengan jelas berupaya mengarahkan publik untuk mendapatkan keuntungan agar medianya diterima oleh publik. Oleh karena itu, permasalahan kesehatan pada saat itu yang notabene menjadi momen Pilkada menjadi muatan yang "seksi". Apalagi permasalahan kesehatan menjadi salah satu program yang dikampanyekan. Faktanya dalam periode Desember 2012-Oktober 2013 terdapat 26 judul yang berkaitan dengan rendahnya akses kesehatan masyarakat pada salah satu media lokal Banyumas. Adapun judul-judul yang telah diterbitkan seperti dilarang sakit, b) untuk negara sah-sah saja berkeluh kesah, c) Kartu jamkesmas dinilai tak tepat sasaran, d) Piutang pasien 1 Miliar lebih, e) kenaikan tarif berobat, dan f) Butuh operasional, warga miskin kesulitan berobat.
Berdasarkan fakta tersebut, peneliti mendapatkan substansi bahwa Bupati dan Wakil Bupati terpilih dan media sebagai policy entrepreneur menggunakan arus politik untuk membuka jendela kebijakan. Hal itu dilakukan dengan cara memanfaatkan kewenangan yang dimiliki, membangun opini publik, dan menciptakan nuansa politik lokal yang mengarah pada permasalahan akses kesehatan. Arus politik ini lah yang terus didiorong untuk membuka policy window. Fakta ini juga ditegaskan oleh Jiani (2010) dan Dominguez (2005) bahwa arus politik memiliki peran yang sangat besar terhadap terbukanya jendela kebijakan.

\section{TEMUAN PENELITIAN}

Berdasarkan penelitian ini, peneliti menemukan fakta bahwa terdapat hubungan yang tidak independen dan kekuatan arus yang tidak simultan antara problem, politics, dan policy streams. Adapun secara konseptual, dapat peneliti gambarkan sebagai berikut: 


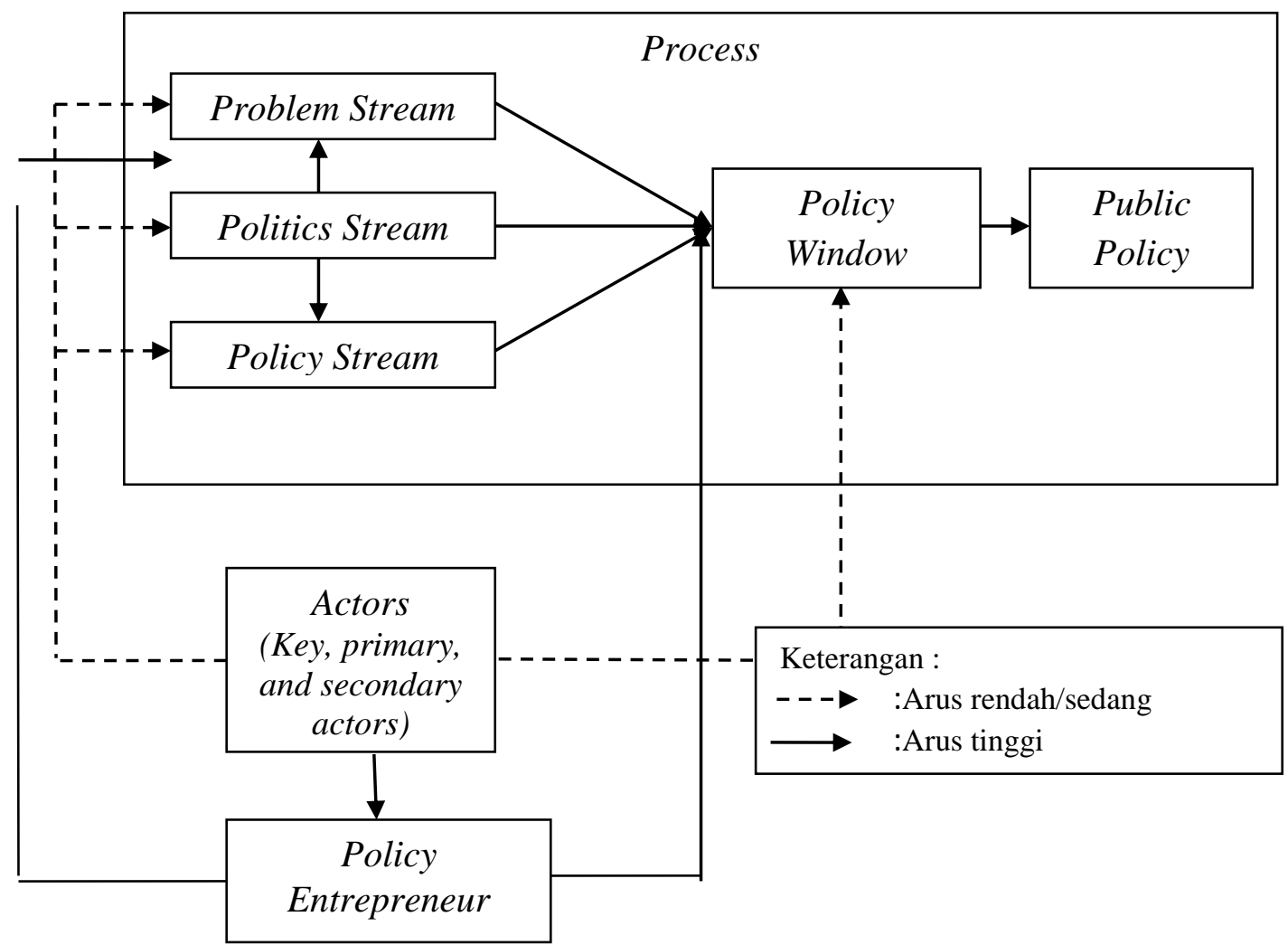

Gambar 2. Pengembangan Model Formulasi Kebijakan John W. Kingdon Berdasarkan Hasil Penelitian Formulasi Kebijakan Kartu Banyumas Sehat

Bagan tersebut menerangkan bahwa political stream memiliki kekuatan yang lebih dominan, dimana arus ini mampu memberikan dorongan pada problem dan policy stream. Oleh karena itu, policy entrepreneur akan menggunakan arus politik lebih dominan dibandingkan arus lain untuk membuka policy window. Kekuatan masing-masing arus inilah yang tidak dijelaskan oleh Kingdon. Berdasarkan hal ini, artinya tidak terdapat hubungan yang murni independen pada masing-masing arus.

\section{E. KESIMPULAN}

Formulasi kebijakan adalah sebuah proses yang kompleks, namun teori Kingdon mampu memberikan gambaran proses tersebut. Oleh karena itu, berdasarkan penelitian formulasi Kebijakan Kartu Banyumas Sehat dapat disimpulkan beberapa hal sebagai berikut:

a. Problem Stream

Konsensus antar policy maker tentang agenda kebijakan akses kesehatan dapat dicapai atas dorongan faktor kajian rasional etika atau dalam istilah Kingdon yaitu indikator, peristiwa besar, dan umpan balik.

b. Policy Stream

Gagasan kebijakan Kartu Banyumas Sehat (KBS) diterima karena adanya pemakluman bersama dari parlemen di tingkat lokal. Jadi parlemen tingkat lokal 
memiliki pengaruh terhadap policy stream.

c. Political Stream

Opini publik dan perubahan pandangan pemerintah merupakan kekuatan yang secara terus menerus membentuk dan mendorong dibuatnya kebijakan jaminan kesehatan daerah atau Kartu Banyumas Sehat.

d. Policy Window

Bupati dan Wakil bupati terpilih serta media adalah aktor yang berperan sebagai policy entrepreneur, dimana aktor tersebut mendorong arus politik lebih dominan untuk membuka jendela kebijakan (policy window).

e. Penelitian ini memberikan rekonstruksi terhadap teori Kingdon dengan memperjelas bahwa masing-masing arus tidak berjalan simultan dan tidak murni independen karena arus politik lebih kuat dibandingkan dengan arus lain.

\section{F. IMPLIKASI}

Penelitian ini secara garis besar memiliki dua implikasi. Secara teoritik seyogyanya peneliti selanjutnya dapat mengkaji model yang telah penulis susun dalam kondisi politik yang berbeda. Hal ini untuk memberikan kepercayaan bahwa ketika kondisi politik lemah, maka dimungkinkan formulasi kebijakan akan gagal.

Secara praktis, penelitian ini memberikan implikasi bahwa terdapat beberapa hal yang sebaiknya dilakukan dalam proses formulasi kebijakan. Pertama, Membuka ruang-ruang diskusi untuk menampung gagasan dan kontrol dalam membahas permasalahanpermasalahan publik baik melalui seminar, diskusi publik, maupun public hearing. Kedua, perlunya membangun transparansi publik dalam setiap tahapan formulasi dengan cara seperti sidang terbuka, memberikan keterangan pers, ataupun bekerjasama dengan media masa untuk menginformasikan proses formulasi kebijakan. Ketiga, menempatkan peran akademisi dalam posisi yang strategis pada setiap pengambilan kebijakan melalui kajian ilmiah yang beretika. Dimana hasil kajian ini dijadikan sebagai salah satu ukuran bagi policy maker dalam pengambilan keputusan.

\section{DAFTAR PUSTAKA}

Alan, C.W. 2008. An Analysis of Policy Agenda Setting: A Study of West Kowloon Cultural District Development. The University of Hongkong

Arifin, A. Komunikasi Politik: FilsafatParadigma-Teori-Tujuan-Strategi dan Komunikasi Politik Indonesia. Yogyakarta: Graha Ilmu

Beland, Daniel. 2005. Ideas and Social Policy: An Institutionalist Perspective. Social Policy and Administration. Vol. 39, No. 1, pp. 1-8

Berg, B.L. 2001. Qualitative Research Methods for The Social Science. United States of America: A Pearson Education Company

Birkmann, et al. 2008. Extreme events and disasters: a window of 
opportunity for change? Analysis of organizational, institutional and political changes, formal and informal responses after megadisasters. Springer Science and Bussines Media. No. 55, pp. 637655

Brannen, J. 1995. Mixing Methods:Qualitative and Quantitative Research. Aldershot: Avebury

Carrillo, I.L.E. 2007. The EU Presidency Agenda for Antiterrorism: A Multiple Stream Analysis. Belgia: University of Munster

Certien, J. 2012. Policy Entepreneur: A Case Study of The 2002 G8 Summit in Kananaskis, Alberta. Canada: University of Saskatchewan

Cohen, et al. 1972. A Garbage Can Model of Organizational Choice. Administrative Science Quarterly, Vol. 17, No.1, pp. 1-25.

Dominguez, C.J. 2005. Collective Action Frame and Policy Windows: The Case of the Project to Export Liquefied natural Gas from Bolivia to California. QEH Working Paper Series. No 127. Queen Elizabeth House, University of Oxford.

Hill, M. 2005. The Public Policy Process Fourth Edition. United Kingdon: Pearson Education Limited

Jenkins, J. dan Les Alm. 2003. Movers and Shakers: A Qualitative Questions on The Role of Policy Entrepreneurs. Department Of Public Administration Journal.
Jaiani, V. dan Andrew B. W. 2010. Policy Windows, Public Opinion, and Policy Ideas: The Evolution of No Child Left Behind. Quality Assurance in Education Journal, Vol. 19, No. 1, pp. 8-27

Kingdon, J.W. 2001. A Model of Agenda Setting with Application: Law Review, Vol. 2, pp. 331

Lewis, D.A. dan Stephen W.T. 2008. Streaming into Baghdad: Kingdon's Model of Agenda Setting and the U.S. Invasion of Iraq. Department of Political Science Frostburg State University, pp. 1-20s

Moleong, Lexy J. 2005. Metode Penelitian Kualitatif. Bandung: PT. Remaja Rosdakarya

Ndlovu, L.A. 2006. An Agenda Setting Analyis: The Application of Kingdon's Framework to the Road Accident Fund (RAF): KwaZulu Natal Pietermaritzburg University

Sugiyono. 2007. Metode Penelitian Kuantitatif, Kualitatif, dan $R \& D$. Bandung: Alfabeta

Teodorovic, J. 2008. Why Education Policies Fail: Multiple Streams Model of Policy Making. Institute for Education Research, Vol. 40, No.2. pp. 22-36

Wibawa, Samodra. 2011. Politik Perumusan Kebijakan Publik. Yogyakarta: Graha Ilmu

Zahariadis, Nikolaos. 2006. The Multiple Streams Framework. pp. 65-68 